\title{
Wing Transmission for a Micromechanical Flying Insect *
}

\author{
R.S. Fearing ${ }^{1}$, K.H. Chiang ${ }^{1}$, M.H. Dickinson ${ }^{2}$, D.L. Pick ${ }^{1,2}$, M. Sitti $^{1}$, and J. $\operatorname{Yan}^{1}$ \\ ${ }^{1}$ Dept. of EE\&CS ${ }^{2}$ Dept. of Integrative Biology \\ University of California \\ Berkeley, CA 94720-1770
}

\begin{abstract}
Flapping wings provide unmatched maneuverability for flying micro-robots. Recent advances in modelling insect aerodynamics show that adequate wing rotation at the end of the stroke is essential for generating adequate fight forces. We developed a thorax structure using four bar frames combined with an extensible fan-fold wing to provide adequate wing stroke and rotation. Flow measurements on a scale model of the beating wing show promising aerodynamics. Calculations using a simple resonant mechanical circuit model show that piezoelectric actuators can generate sufficient power, force and stroke to drive the wings at 150 $\mathrm{Hz}$.
\end{abstract}

\section{Introduction}

Flapping flight for micro-robots is not only an intriguing mode of locomotion, but provides maneuverability not obtainable with fixed or rotary wing aircraft. Insects can fly with a payload equal to their body mass, and have peak accelerations approaching $10 \mathrm{~m} / \mathrm{s}^{2}$ [May 1991]. Although they require relatively still air, flying micro-robots can fly over terrain which would be impassable for a legged micro-robot. Following the initial vision of Flynn [1987], pioneering work in micro-robotic flight was started by Shimoyama [Shimoyama et al 1993; Kubo et al 1994; Miki and Shimoyama 1998] and more recently, milli-robotic flapping flight by [Cox, Garcia, and Goldfarb, 1998].

This paper considers the kinematic and power requirements for a micro-robotic flying device using beating wings, and presents an initial design of a tho$\operatorname{rax}$ for the device. As shown in Figure 1, we will be using flexural 4 bar elements to provide sufficient wing stroke, and a compliant wing which can deform to provide rotation. A summary of the MFI component dimensions is given in Table 1. Further work is

*This work was funded by ONR MURI N00014-98-1-0671, ONR DURIP N00014-99-1-0720 and DARPA.

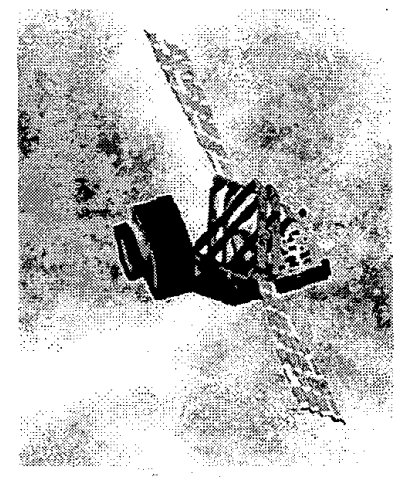

Figure 1: Conceptual drawing of micromechanical flying insect.

\begin{tabular}{|l|c|r|}
\hline MFI component & size & total mass \\
\hline \hline $\begin{array}{l}\text { 4-bar frames } \\
\text { (2 per wing) }\end{array}$ & links $5,5,4,0.7 \mathrm{~mm}$ & $20 \mathrm{mg}$ \\
\hline $\begin{array}{l}1 \mathrm{~mm} \text { box beam } \\
\text { base frame (mm) }\end{array}$ & $10 \times 4 \times 1 \mathrm{~mm}$ & $8 \mathrm{mg}$ \\
\hline $\begin{array}{l}\text { piezo actuator } \\
\text { (2 per frame) }\end{array}$ & $\begin{array}{l}0.25 \times 5 \times 0.2 \mathrm{~mm} \\
\text { (total } 8 \text { actuators) }\end{array}$ & $15 \mathrm{mg}$ \\
\hline $\begin{array}{l}\text { wings } \\
\text { (polyester) }\end{array}$ & $5 \times 10 \times .01 \mathrm{~mm}$ & $3 \mathrm{mg}$ \\
\hline total structure & & $43 \mathrm{mg}$ \\
\hline
\end{tabular}

Table 1: Components of final size MFI. Structure will be made from $10 \mu \mathrm{m}$ thick 302 stainless.

required with models and prototypes before solving the critical issues of control, sensing, or power supply.

As a design target for the micromechanical flying insect (MFI), we are using the blowfly Calliphora, which has a mass of $100 \mathrm{mg}$, wing length of $11 \mathrm{~mm}$, wing beat frequency of $150 \mathrm{~Hz}$, and actuator power of about $8 \mathrm{~mW}$. At this size scale, the current best understanding of non-steady state aerodynamics comes from experimental observations of real insects and kinematically similar mockups [Ellington et al 1996; Dickinson and Götz 1996]. 


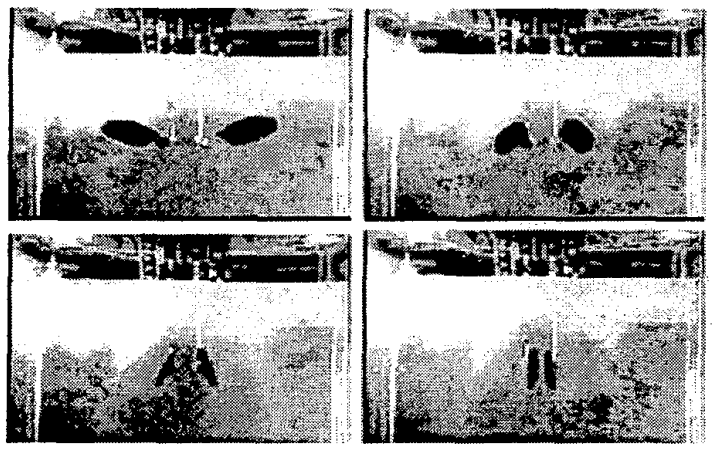

Figure 2: Robofly apparatus in mineral oil tank.

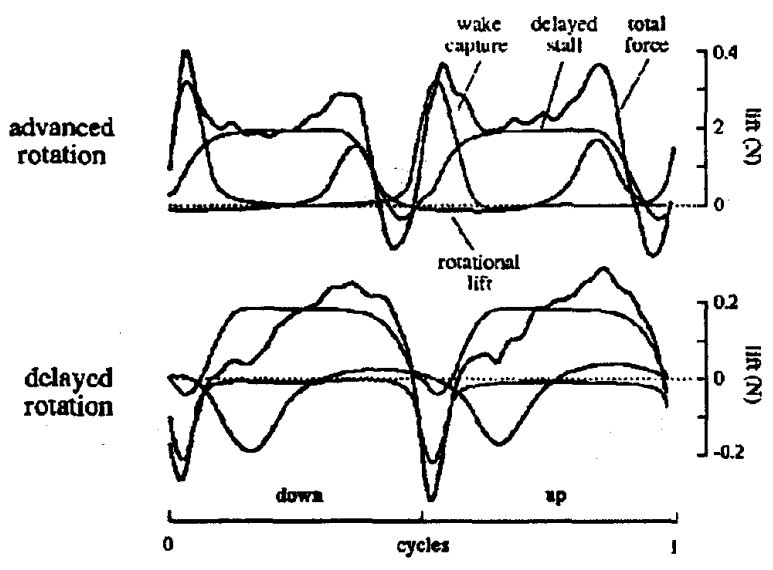

Figure 3: Experimental data from Robofly. The timing of wing rotation has a major effect on net lift. Advanced rotation, before the end of the stroke, significantly increases lift. (Adapted from Dickinson et al 1999).

\section{Insect Unsteady Aerodynamics}

The RoboFly apparatus (Figure 2) [Dickinson et al 1999], consists of a two-winged system driven by 3 stepping motors, which can closely mimic the stroke kinematics of a fruit fly, (or other arbitrary kinematics). Strain gauges are used to measure instantaneous wing forces, and the integral of forces around a closed wing beat cycle can be measured to determine net flight forces. Robofly running with wing beat of $1 / 6$ $\mathrm{Hz}$ in oil has the same Reynold's number as a fruitfly with wing beat of $220 \mathrm{~Hz}$ in air. Flow was visualized using air bubbles in the oil tank and particle image velocimetry (PIV).

Results with the Robofly apparatus have identified the 3 key aerodynamic mechanisms used by insects: delayed stall, wake capture, and rotational circulation

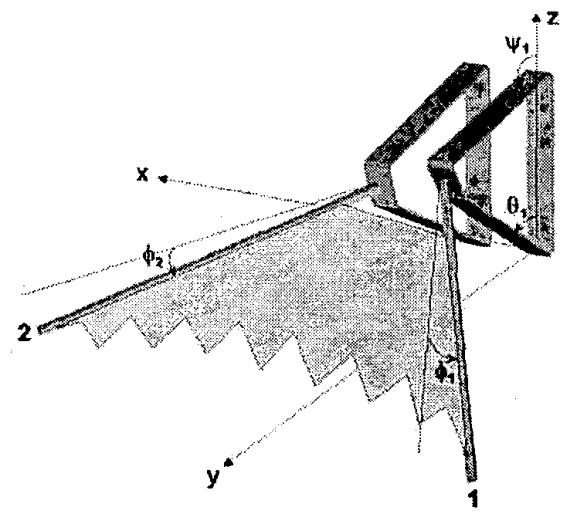

Figure 5: Wing kinematics parameters for two 4 bar frames and wing.

[Dickinson et al 1999]. Dickinson et al have found wing trajectories which generate peak lift forces of four times the equivalent insect weight. The timing of an equivalent of a back spin motion at the bottom of the wing stroke can change the net lift from positive to negative (Figure 3 ). The second key finding was the significant forces generated by wake capture at the top and bottom of the stroke. These results are directly relevant to the wing kinematics of the MFI, as it appears that a rapid wing rotation of 90 degrees needs to occur before the end of the down stroke to create adequate lift. This wing rotation and the resulting flow patterns can be seen in a sequence of images taken of Drosophila (Figure 4).

\section{Thorax and Wing Design}

We know that insect flight at the centimeter scale requires both large stroke amplitude and wing rotation [Dickinson et al 1999]. Drosophila uses a wing stroke of $160^{\circ}$ combined with wing rotation of over $90^{\circ}$. Wing rotation is the challenging part of the design. The insect thorax uses a complicated arrangement of linkages and cams [Nachtigall, Wisser, and Eisinger, 1998] which is not yet fully understood, and is likely to difficult to fabricate.

Our thorax design uses separate four bar frames to control the leading and trailing edges of a fanfold compliant wing, as shown in Figure 5. From simple geometric considerations, the total wing spar stroke angle can readily be shown to be $\theta_{w}=2 \theta_{\min }$ where $\theta_{\min }$ is the smaller base angle $\theta_{1}$ when the 4 bar mechanism is in a triangle configuration. The motion magnification of the 4 bar will allow a piezoelectric unimorph with small angle deflection to be used as the actuator as described in Section 5. 

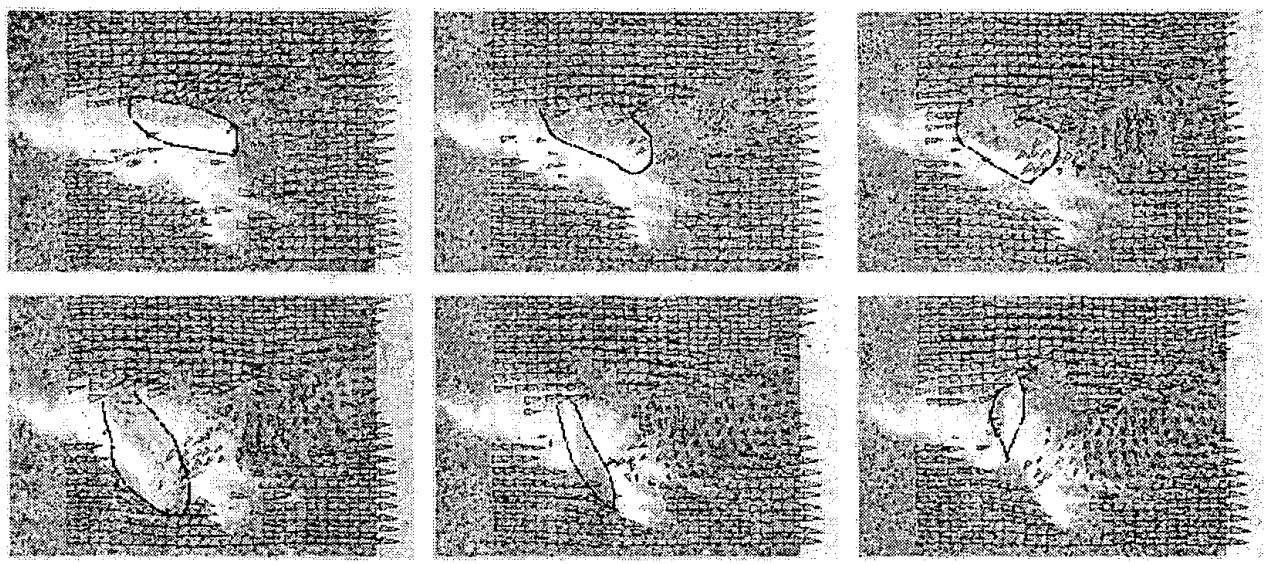

Figure 4: Flow for tethered Drosophila, with wing frequency $220 \mathrm{~Hz}$. Images at $200 \mu s$ intervals (left to right, top to bottom) starting $1.4 \mathrm{~ms}$ from top of wing stroke. Note wing rotates $\approx 90^{\circ}$ in $0.6 \mathrm{~ms}$.

We analyze the kinematics of the thorax/wing structure to obtain desired flapping and rotational motions of the wing. The two wing spars are rotated by controlling the $\theta_{i}$ crank angles $(i=1,2)$ :

$$
\begin{aligned}
\psi_{i}\left(\theta_{i}\right) & =\tan ^{-1}(B / A) \pm \cos ^{-1}\left(C / \sqrt{A^{2}+B^{2}}\right) \\
\phi_{i}\left(\theta_{i}\right) & =\tan ^{-1}\left(\frac{b \sin \psi_{i}-a \sin \theta_{i}}{g+b \cos \psi_{i}-a \cos \theta_{i}}\right), \\
A & =2 a b \cos \theta_{i}-2 g b \\
B & =2 a b \sin \theta_{i} \\
C & =g^{2}+b^{2}+a^{2}-h^{2}-2 a g \cos \theta_{i}
\end{aligned}
$$

where $a, b, g, h$ are the 4 link lengths. A solution exists if and only if $A^{2}+B^{2}-C^{2} \geq 0$.

\subsection{Thorax and Wing Construction}

Thorax construction materials should be chosen for high stress limits, high endurance, and low loss (Table 2). The insect thorax is constructed from cuticle with resilin connections [Jensen and Weis-Fogh, 1962], which compares very well in stress limits with stainless steel. Polysilicon is a good structural material, but is harder to handle and process than stainless. Note that peak stress must be limited to maintain life. This can be done with thin materials, and by keeping the overall system $Q$ low since high $Q$ increases dynamic stresses. While the overall $Q$ of the actuator-wing system is predicted to be only $\approx 2$ (Section 5.2 ) due to wing and actuator dissipation, for reasonable efficiency, the internal dissipation of the structural material [Hosaka, Itao, and Kuroda, 1994] should be kept low.

The four bar frames need to have a very high strength-to-weight ratio. As pointed out by Yeh et al [1994], hollow beams can be several orders of magnitude stiffer than a solid beam of the same mass, and we use the same principle. Solid rectangular and triangular beams of width $w$ and height $h$ have respective cross-sectional moments of inertia [13]:

$$
I_{\text {rect }}=w h^{3} / 12 \text { and } I_{t r i}=w h^{3} / 36 .
$$

The stiffness of a cantilever beam of length $l$ and modulus $E$ in simple bending due to a concentrated force at the end is given by

$$
k=3 E I / l^{3} .
$$

A hollow beam has cross-sectional moment of inertia given by the difference in moment of inertia between a solid beam and a beam smaller by the wall thickness. Consider the links of the 4 bar structure shown in Figure 5, with a mass of $0.24 \mathrm{mg} / \mathrm{mm}$ length. For the same mass, we could use either a $30 \mu \mathrm{m}$ thick cantilever, $1 \mathrm{~mm}$ wide, with cross-sectional moment of inertia $2.3 \times 10^{-18} \mathrm{~m}^{4}$, or a $1 \mathrm{~mm}$ triangular beam constructed by folding a $10 \mu \mathrm{m}$ thick sheet, with crosssectional moment of inertia $700 \times 10^{-18} \mathrm{~m}^{4}$. Hence, the hollow triangular beam is approximately 300 times stiffer than the solid beam for the same mass. An 8 $\mathrm{mm}$ long box beam made from 302 stainless would have a stiffness of $7000 \mathrm{~N} / \mathrm{m}$. A peak load on the structure from the actuators of $100 \mathrm{mN}$ (see Section 5) would cause a deflection of less than $130 \mu \mathrm{m}$, thus this beam is stiff enough.

Since pin joints are difficult to place in a $1 \mathrm{~mm}$ structure without friction, wear, reinforcement, and alignment problems, we use flexural joints. As shown 


\begin{tabular}{|c|c|c|c|c|c|c|}
\hline property & music wire & poly silicon & 302 stainless & polyester & cuticle & resilin \\
\hline $\begin{array}{l}\text { Elastic Modulus } \mathrm{E} \mathrm{Nm}^{-2} \\
\text { yield stress } \mathrm{Nm}^{-2} \\
\text { ultimate extension }\end{array}$ & $\begin{array}{c}200 \times 10^{9} \\
4 \times 10^{9} \\
2 \%\end{array}$ & $\begin{array}{c}140 \times 10^{9} \\
0.7 \times 10^{9} \\
.5 \%\end{array}$ & $\begin{array}{c}181 \times 10^{9} \\
1 \times 10^{9} \\
0.5 \%\end{array}$ & $\begin{array}{c}3.6 \times 10^{9} \\
55 \times 10^{6} \\
124 \%\end{array}$ & $\begin{array}{l}10 \times 10^{9} \\
0.4 \times 10^{9} \\
2-3 \%\end{array}$ & $\begin{array}{l}2 \times 10^{6} \\
300 \%\end{array}$ \\
\hline $\begin{array}{l}\text { endurance limit } N m^{-2} \\
\left(>10^{6} \text { cycles }\right)\end{array}$ & $\begin{array}{l}10^{9} \\
0.5 \%\end{array}$ & $\begin{array}{c}0.7 \times 10^{9} \\
0.5 \%\end{array}$ & $\begin{array}{l}0.5 \times 10^{9} \\
0.3 \%\end{array}$ & $?$ & ? & ? \\
\hline$Q=\frac{\pi}{\sqrt{0 s s f a c t a r}}$ & 200 & $10^{4}$ & $?$ & $?$ & 30 & $>100$ \\
\hline density $\mathrm{mg} / \mathrm{mm}^{3}$ & 7.9 & 2.3 & 7.9 & 1.4 & 1.3 & $?$ \\
\hline wave velocity $\sqrt{\frac{E}{\rho}\left(m s^{-1}\right)}$ & 5000 & 7800 & 5000 & 1600 & 2800 & $?$ \\
\hline reference & Oberg 88 & Keller 98 & matls.com & matls.com & Jensen 62 & Jensen 62 \\
\hline
\end{tabular}

Table 2: Material properties for thorax and wing.

in Figure 6, the 4 bar mechanism including box beam links and flexural joints can be fabricated by folding a sheet of photo-etched or laser cut stainless steel. The side and top links are triangular beams and the base is a box beam for easier attachment to the MFI frame.

We have used glass fiber reinforcing at the joints to increase lifetime with large bend angles of the $5 \times$ model, but a better long term approach is to use the "split tube flexure" of Goldfarb and Speich [1998] to obtain a more precise center of rotation for the joint and improved lifetime. Currently, the structures are folded manually using fixtures and bonded using cyanoacrylate adhesive. Automatic folding of microstructures is quite feasible, particularly using simple fixtures and a motion planning approach such as described by Lu and Akella [1999].

The wing for the $5 \times$ mockup is made from folded $25 \mu \mathrm{m}$ thick polyester bonded to plastic wing spars as shown in Figure 7. The increased drag caused by the fan-folds is not thought to be significant at the low Reynolds number flow of the MFI.

\section{Preliminary Flow Results with $5 \times$ Mockup}

The $5 \mathrm{x}$ wing mockup can be driven statically with a stroke of $\pm 60^{\circ}$ or a rotation of $\pm 45^{\circ}$. Figure 8 shows PIV images of this wing being driven at $f=17 \mathrm{~Hz}$ in a wind tunnel operating with a flow of $0.14 \mathrm{~m} / \mathrm{s}$ (to the right). Ellington [1984] approximates the mean Reynolds number during a wing stroke as

$$
R e=\frac{S f \Phi}{\nu}
$$

where $\nu=1.6 \times 10^{-4} \mathrm{~m}^{2} / \mathrm{s}$ is the kinematic viscosity of air, $S=32 \mathrm{~cm}^{2}$ is the wing surface area for both wings, and $\Phi=1 \mathrm{rad}$ is the stroke amplitude. In this case, $R e=340$ which is comparable to the blowfly. Processing of the PIV images shows that induced velocities

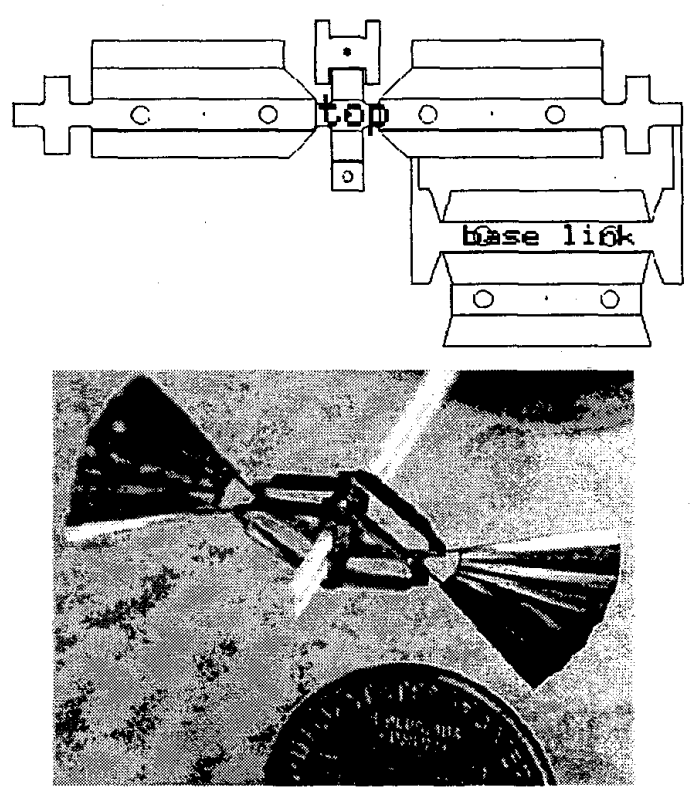

Figure 6: Flat pattern for one thorax 4 bar flexural frame, and assembled thorax at $1.5 \times$ scale.

as high as $1.65 \mathrm{~m} / \mathrm{s}$ and $0.79 \mathrm{~m} / \mathrm{s}$ were recorded during the upstroke and downstroke, respectively, with peak wing-tip speeds of $2 \mathrm{~m} / \mathrm{s}$.

Visually, there are two interesting results that can be seen from the PIV data. Firstly, there is a significant momentum change in the particles directly under the wing from the end of the upstroke to the beginning of the downstroke and this would indicate a period of large lift forces. Secondly, vortex shedding at the trailing edge of the wing is readily apparent as the wing finishes the downstroke and begins the upstroke. 

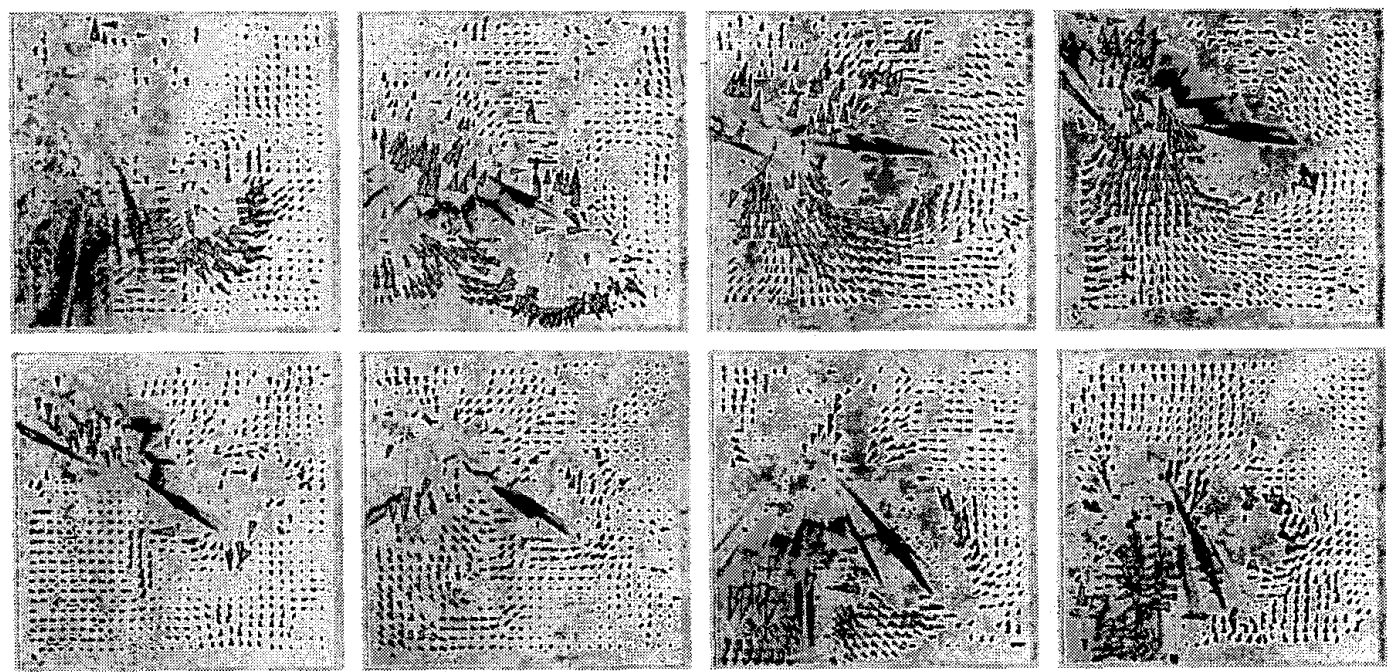

Figure 8: Flow structures measured using PIV for $50 \mathrm{~mm}$ wing beating at $17 \mathrm{~Hz}$, showing complete wing stroke starting at bottom of stroke. Dark line is laser light sheet (negative image).
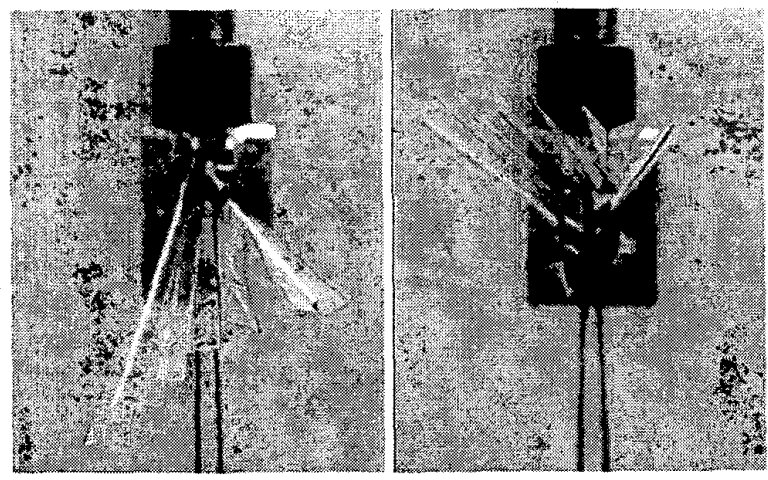

Figure 7: Static wing motion using voice coil actuator on $5 \times$ scale prototype.

\section{Actuation, Transmission, and Power}

The previous sections have discussed the design and fabrication of a prototype thorax for the MFI. The next critical issue is the delivery of sufficient mechanical power to the wings. Insect flight muscle delivers on the order of $100 \mathrm{Wkg}^{-1}$ to the wings [Ellington 1985]. To avoid losses associated with accelerating inertial loads, real insects such as blowflies and fruitflies drive their wings at mechanical resonance [Sotavalta 1952]. We use the same principle in our thorax design.

The exact MFI power requirement will depend on the non-linear kinematics of the two 4 bar structures and fan-fold wing, actuator compliance, and non-steady state aerodynamic loading and can not be

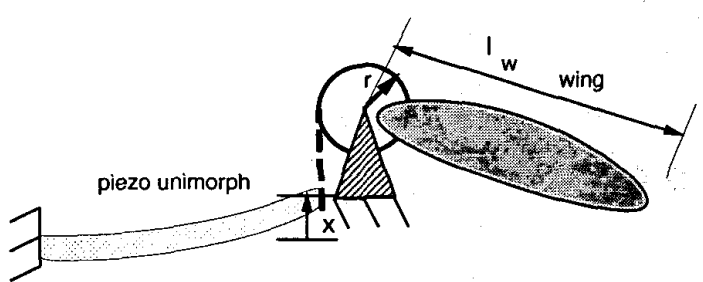

Figure 9: Mechanical schematic of actuator and wing connection. Virtual pulley represents thorax kinematics and motion amplification.

exactly modelled with current flow simulation tools. We thus examine actuating a single equivalent linear damping load through a simple pulley, which provides a rough bound on the power required to drive two wings generating sufficient lifting force. We consider a piezoelectric unimorph actuator driving a wing mounted on a pulley of radius $r$ as shown in Figure 9. The equivalent wing damping is chosen such that the force at the end of the wing at maximum wing tip velocity is equal to twice the weight of the MFI:

$$
B_{L}=2 \frac{m_{M F I} g l_{w}}{r^{2} \omega \theta}
$$

where $m_{M F I}$ is the mass, $l_{w}$ is the length of the wing, $\omega$ is the wing beat frequency, and $\theta$ is the wing stroke amplitude ( $1 / 2$ the total wing stroke).

For simplicity, we assume the inertia of the wing can be modelled as a point mass $\left(m_{w}\right)$ at $r_{w}=5.0 \mathrm{~mm}$ 


\begin{tabular}{|l|c|}
\hline parameter & value \\
\hline wing pulley radius $r$ & $0.5 \times 10^{-3} \mathrm{~m}$ \\
wing point mass $m_{w}$ & $0.5 \times 10^{-6}<m_{w}<2.5 \times 10^{-6}$ \\
wing inertia & $12 \times 10^{-12}<J<60 \times 10^{-12} \mathrm{kgm}^{2}$ \\
wing beat $\omega$ & $2 \pi 150 \mathrm{sec}^{-1}$ \\
wing amplitude & $\theta=1$ radian \\
load force $F_{L}$ & $2.9 \times 10^{-2} \mathrm{~N}$ \\
load damping $B_{L}$ & $6.4 \times 10^{-2} \mathrm{Nsm} \mathrm{m}^{-1}$ \\
load mass $M_{L}$ & $0.5 \times 10^{-4}<M_{L}<2.5 \times 10^{-4} \mathrm{~kg}$ \\
load stiffness $K_{L}$ & chosen for resonance \\
required power & $7.0 \times 10^{-3} \mathrm{~W}$ \\
\hline
\end{tabular}

Table 3: Model assumptions for MFI using linear damper model.

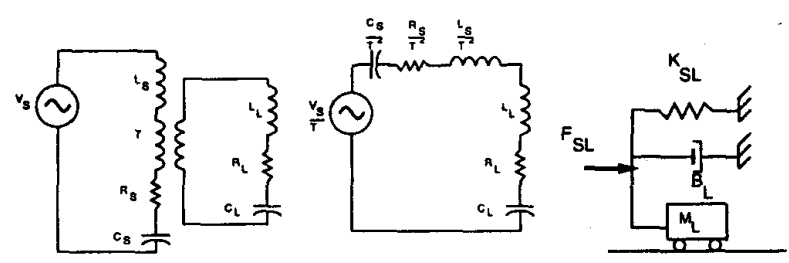

Figure 10: Electrical and mechanical equivalent resonant models for actuator, thorax, and wing.

from the joint. The thorax inertia may also be lumped into this parameter. Similarly to wing damping, wing inertia is mapped into a linear inertia $M_{L}$ through a "wing pulley" of radius $r$.

$$
M_{L}=\frac{m_{w} r_{w}^{2}}{r^{2}}
$$

The load stiffness $K_{L}$ can be chosen to tune the system to resonance. The resulting load parameters are summarized in Table 3.

\subsection{Transmission}

For many actuators, there is a large mismatch between source and load impedances. In addition, the large stiffness of the actuator would require too large a mass for resonance to be carried by the MFI. The leverage provided by the wing pulley (or equivalently the 4 bar thorax) can be modelled as a lossless transformer as shown in Figure 10. The actuator can be modelled as a voltage (force) source with equivalent damping $\left(R_{S}\right)$, stiffness $\left(C_{S}^{-1}\right)$, and inertia $\left(L_{S}\right)$. The thorax is modeled as a transformer with coupling ratio $T$, and the wing-hinge combination (the load) has damping $\left(R_{L}\right)$, stiffness $\left(C_{L}^{-1}\right)$, and inertia $\left(L_{L}\right)$. Typically, for unmatched piezo and load impedances, the stiffness of the actuator is much greater than the load stiffness, and the actuator damping is much less than the equivalent wing damping. Hence the efficiency is

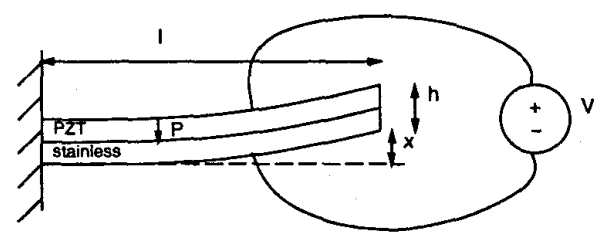

Figure 11: Piezoelectric unimorph actuator.

close to $100 \%$ but the power density is quite low compared to matched conditions.

The output force from the lever $F_{S L}$ scales proportionally with input force $F_{S}$, while output position $x_{S L}$ scales inversely with input position $x_{S}$. Hence, with transformer ratio $T: K_{S L}=K_{S} / T^{2}, B_{S L}=B_{S} / T^{2}$, $M_{S L}=M_{S} / T^{2}$, and $F_{S L}=F_{S} / T$. The attachment point of the actuator to the 4 bar structure, and the 4 bar link lengths determine $T$.

For resonance, the equivalent mass of the actuator $M_{S L}$ combined with the wing inertia $M_{L}$ must be chosen to have the same magnitude reactance at the resonant frequency $\omega$ as $K_{S L}$. The equivalent mass of the piezo actuator is negligible compared to the wing inertia. Thus the maximum transformed actuator stiffness is $K_{S L \max }=\omega^{2} M_{L \max }$, where $M_{L \max }$ is the maximum translational equivalent wing inertia. With the assumed wing pulley radius $r=0.5 \mathrm{~mm}$, the maximum actuator stiffness is $230 \mathrm{Nm}^{-1}$ at $150 \mathrm{~Hz}$.

Using a figure of $7 \mathrm{~mW}$ for actuator power, basic $\mathrm{AC}$ circuit analysis shows the minimum actuator force $F_{S L}$ for matched loads $\left(B_{S L} \approx B_{L}\right)$ and unmatched loads $\left(B_{S L} \ll B_{L}\right)$ is respectively found to be

$$
F_{S L \min }=\sqrt{8 B_{L} P_{L}} \text { and } F_{S L \text { min }}=\sqrt{2 B_{L} P_{L}} \text {. }
$$

A low internal damping actuator needs only half as much force as a matched damping actuator and will run at higher efficiency, while requiring greater actuator mass. A piezoelectric actuator with low internal damping will need to provide $29 \mathrm{mN}$ at $150 \mathrm{~Hz}$ to provide sufficient power.

\subsection{Piezoelectric Actuation}

Piezoelectric materials in $d_{31}$ mode have too small a displacement and too high a stiffness to work well at wing beat frequencies of $150 \mathrm{~Hz}$. A matching network could be used, but the high $Q$ of the actuator system causes excessive stress in the piezo. A piezoelectric slab bonded to an elastic layer, forms a unimorph which bends when an electric field is applied. A unimorph configuration as shown in Figure 11 gives a blocked force (following the bimorph analysis of Smits 
et al [1991]):

$$
F_{S} \approx \frac{3}{16} Y_{11} d_{31} \frac{h w}{l} E_{3} h
$$

where $Y_{11}$ is stiffness, $E_{3}$ is electric field, $w$ is width, and $d_{31}$ is the piezoelectric constant in $m V^{-1}$. The free displacement of the unimorph cantilever is given by [Smits et al 1991]:

$$
x_{S}=\frac{3}{4} d_{31} \frac{l^{2}}{h^{2}} E_{3} h .
$$

Thus the actuator stiffness is just $K_{S}=F_{S} / x_{S}$.

Alternatively, a bimorph structure consisting of two layers of piezoelectric material would give twice the displacement and twice the force. However, the power limit for the actuator is typically determined by the dynamic stress limit [Berlincourt et al 1964]. A prestressed unimorph, such as the Face Int. THUNDER, can be safely operated with almost 10 times greater fields than a bimorph, giving a 25 times greater power density.

The resonant frequency of a homogeneous cantilever with density $\rho$ is

$$
\omega_{0}=\frac{h}{l^{2}} \sqrt{\frac{Y_{11}}{\rho}} .
$$

Note that the cantilever resonant frequency is quite large compared to the wing resonance. Using eq. 10 and the relation between $Q$ and damping for a series resonant circuit, the unimorph damping can be estimated as:

$$
B_{S}=\frac{K_{S}}{Q \omega_{o}},
$$

where the elastic layer damping has been assumed small compared to the piezo damping. It is important to note that the quoted mechanical $Q$ for piezoelectric materials is usually at low stress, as in a sensor application. At high stress the mechanical $Q$ is about $10 \%$ of the unstressed $Q$. The MFI actuator will be running at high stress.

Using the resonant circuit model of Figure 10, we analyzed power requirements and wing stroke amplitude assuming a piezoelectric unimorph (Figure 9). We obtained design parameters as given in Table 4, using an actuator $5 \times 0.2 \times 2 \mathrm{~mm}^{3}$ in size. A $15 \mathrm{mg}$ mass of PZT5H can generate the $7 \mathrm{~mW}$ of mechanical power required at a frequency of $150 \mathrm{~Hz}$, using a driving voltage of 200 volts. Note that this is the

\begin{tabular}{|c|c|}
\hline parameter & value \\
\hline $\begin{array}{l}\text { frequency } \omega \\
\text { high } E_{3} \text { mechanical } Q \\
\text { material stiffness } Y_{11} \\
\text { piezoelectric constant } d_{31} \\
\text { ideal actuator power density } \\
\text { actuator dimensions } l w h \\
\text { actuator mass } \\
\text { applied field } E_{3}\end{array}$ & 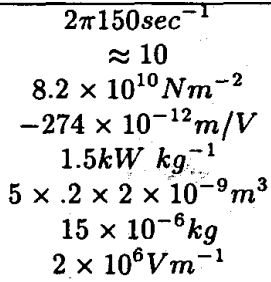 \\
\hline $\begin{array}{l}\text { blocked force } F_{S} \\
\text { free displacement } x_{D C} \\
\text { resonant freq. } \omega_{o} \\
K_{S}=F_{S} / x_{D C} \\
M_{S}=K_{S} / \omega_{o}^{2} \\
B_{S}\end{array}$ & $\begin{array}{c}0.135 \mathrm{~N} \\
5.1 \times 10^{-5} \mathrm{~m} \\
4.4 \times 10^{4} \mathrm{sec}^{-1} \\
2600 \mathrm{Nm}^{-1} \\
1.4 \times 10^{-4} \mathrm{~kg}^{-1} \\
.134 \mathrm{Nsm}^{-1} \\
\end{array}$ \\
\hline $\begin{array}{l}\text { transmission ratio } T \\
F_{S L} \\
K_{S L} \\
B_{S L} \\
M_{S L} \\
\text { required } M_{L}\end{array}$ & $\begin{array}{c}4.5 \\
30 \mathrm{mN} \\
130 \mathrm{Nm}^{-1} \\
2.9 \times 10^{-3} \mathrm{Nsm}^{-1} \\
6.7 \times 10^{-6} \mathrm{~kg} \\
1.4 \times 10^{-4} \mathrm{~kg}\end{array}$ \\
\hline $\begin{array}{l}\text { wing stroke at } 150 \mathrm{~Hz} \\
\text { wing power at } 150 \mathrm{~Hz} \\
\text { overall } Q \\
\text { efficiency } \eta \\
\text { actuator power density }\end{array}$ & $\begin{array}{c}110^{\circ} \\
6.5 \mathrm{~mW} \\
2.1 \\
95.5 \% \\
400 \mathrm{~W} \mathrm{~kg}^{-1}\end{array}$ \\
\hline $\begin{array}{l}\text { peak beam stress } \\
\text { peak beam strain (compressive) } \\
\text { peak beam deflection } x_{S}\end{array}$ & $\begin{array}{c}1.2 \times 10^{8} \mathrm{Nm}^{-2} \\
0.15 \% \\
1 \times 10^{-4} \mathrm{~m}\end{array}$ \\
\hline
\end{tabular}
total actuator volume required for both wings. Calculations show the mechanical efficiency is better than $95 \%$. (Electrical efficiency can be readily calculated
Table 4: Model assumptions for PZT5 actuation of both wings using a pre-stressed unimorph.

considering the power supply source impedance as described in Stein et al [1994].) This actuator is limited by its strength to peak tensile strains less than $0.1 \%$. The wing power and amplitude for this model are shown in Figure 12. Our analysis of alternative piezo materials such as single-crystal PMNPT shows even better performance, but single-crystal PMNPT is currently difficult to obtain.

\section{Conclusion}

At this stage in the MFI design, we have a good understanding of the necessary wing kinematics, forces; velocities and power from measurements on Robofly and real insects. We have designed kinematic structures using folded stainless steel which give adequate wing motion when driven by external (high power) actuators. Using appropriate fixturing, folding stainless steel is feasible at the final size. Current flexure life time for the $5 \times$ structure is on the order of $10^{4}$ cycles; using improved flexural elements, we should be able to 

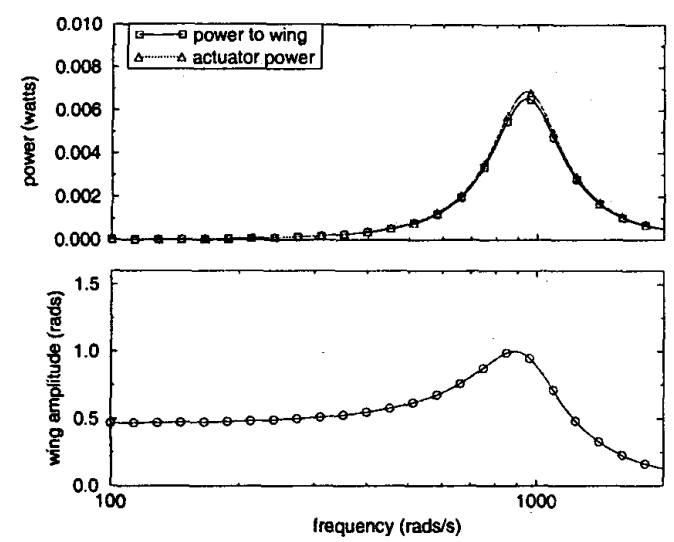

Figure 12: Wing power and wing amplitude for PZT$5 \mathrm{H}$ piezo unimorph. Predicted performance is adequate for flight.

achieve our goal of 1 million wing beats before failure.

In the next stage of the project, we will be quantifying flight forces on the $5 \times$ scale MFI mockup using force sensors mounted on the wing spars, in combination with PIV. Our plan is to develop closed-loop wing controllers which can react to wing forces and modify wing stroke patterns as needed to achieve stable flight.

\section{Acknowledgments}

The authors thank A. Majumdar, K. Pister, T. Sands, and S. Sane for helpful discussions and insights, and Jeff Thompson for laser cutting tools.

\section{References}

[1] D.A. Berlincourt, D.R. Curran, and H. Jaffe, "Piezoelectric and Piezomagnetic Materials and Their Function in Transducers', in Physical Acoustics: Principles and Methods, edited by W.P Mason, New York: Academic Press 1964.

[2] A. Cox, E. Garcia, and M. Goldfarb, "Actuator Development for a Flapping Microbotic Microaerial Vehicle", SPIE Microrobotics Symposium, Nov. 1998, Boston.

[3] M. H. Dickinson and K. G. Götz, "The wake dynamics and flight forces of the fruit fly, Drosophila melanogaster," J. Exp. Biol., vol. 199, pp. 2085-2104, (1996)

[4] M.H. Dickinson, F-O. Lehmann, and S.P. Sane, "Wing Rotation and the Aerodynamic Basis of Insect Flight", Science, vol. 284, pp. 1954-1960, 18 June 1999

[5] C.P. Ellington, C. van den Berg, A.P. Willmot, and A.L.R. Thomas, "Leading edge vortices in insect flight", Nature, vol. 384, pp. 626-630, 19/26 Dec. 1996.

[6] C.P. Ellington, "Power and Efficiency of Insect Flight Muscle", Jnl. of Experimental Biology, vol. 115, pp. 293-304, 1985.

[7] C.P. Ellington, "The Aerodynamics of Hovering Insect Flight. 6. Lift and Power Requirements," Philos. Trans. Royal Society $B$, vol. 305 , no. 1122 , pp. 145-181, 1984.
[8] A.M. Flynn, "Gnat Robots (and How they will change Robotics)", IEEE MicroRobots and Teleoperators Workshop, Hyannis, MA Nov. 9-11, 1987.

[9] M. Goldfarb and J.E. Speich, "Eliminating Non-Smooth Nonlinearities with Compliant Manipulator Design", Proc. American Control Con., pp. 2118-2122, Philadelphia, PA June 1998.

[10] H. Hosaka, K. Itao, and S. Kuroda, "Evaluation of Energy Dissipation Mechanisms in Vibrational Microactuators", IEEE Micro Electro Mechanical Systems, pp. 193-198, Oiso, Japan, Jan. 25-28, 1994.

[11] M. Jensen and T. Weis-Fogh, "Biology and Physics of Locust Flight. V. Strength and Elasticity of Locust Cuticle", Phil. Transactions, vol. 245, B. 721, pp. 137-169, October 1962.

[12] C. Keller, Microfabricated High Aspect Ratio Silicon Flexures, EI Cerrito, CA: MEMS Precision Instruments 1998. (Also see www.memspi.com).

[13] Mark's Standard Handbook for Mechanical Engineers, New York: McGraw-Hill.

[14] L. Lu and S. Akella, "Folding Cartons with Fixtures: A Motion Planning Approach", IEEE Int. Conf. Robotics and Automation, pp. 1570-1576, Detroit, Michigan, May 1999

[15] M.L. May, "Dragonfly Flight: Power Requirements at High Speed and Acceleration", Jnl. of Experimental Biology, vol. 158, pp. 325-342, 1991.

[16] N. Miki and I. Shimoyama, "Analysis of the Flight Performance of Small Magnetic Rotating Wings for Use in Microrobots", IEEE Int. Conf. Robotics and Automation, pp. 30653070, Leuven, Belgium, May 1998.

[17] W. Nachtigall, A. Wisser, and D. Eisinger, "Flight of the Honey Bee. VIII. Functional Elements and mechanics of the 'flight motor' and the wing joint - one of the most complicated gear-mechanisms in the animal kingdom." Jnl. Comp. Physiol. $B$, vol. 168 , pp. $323-344,1998$.

[18] Y. Kubo, I. Shimoyama, T. Kaneda, and H. Miura, "Study on Wings of Flying Microrobots", IEEE Int. Conf. on Robotics and Automation, pp. 834-839, San Diego, CA, May 8-13, 1994.

[19] E. Oberg, F.D. Jones, and H.L. Horton, Machinery's Handbook, New York: Industrial Press, 1988.

[20] I. Shimoyama, H. Miura, K. Suzuki, Y. Ezura, "Insect-Like Microrobots with External Skeletons", IEEE Control Systems Magazine, pp. 37-41, 1993.

[21] J.G. Smits, S.I. Dahlke, and T.K. Cooney, "The Constituent Equations of Piezoelectric Bimorphs", Sensors and Actuators $A$, vol. 28, pp. 41-61, 1991 .

[22] A. Sotavalta, "The Wing Stroke Frequency of Insects in Wing Mutilation and Loading Experiments at Sub-atmospheric Pressure", Am. Zool. Soc., vol. 15, no.2, pp. 1-67, 1952.

[23] S.C. Stein, C. Liang, and C.A. Rogers, "Power Consumption of piezoelectric actuators driving a simply supported Beam Considering Fluid Coupling", Jnl. Acoust. Soc. Am., vol. 96, no 3, pp. 598-1604, Sept. 1994 .

[24] R. Yeh, E.J. Kruglick, M. Klitzke, and K.S.J. Pister, "Towards an Articulated Silicon Microrobot" Winter Annual Meeting, $A S M E$, Dec. 1994 